\title{
Fuzzy $\bar{X}$ and $S$ Control Charts Based on Confidence Intervals
}

\author{
Nilufer Pekin Alakoc ${ }^{1 *}$ \\ ${ }^{1}$ College of Engineering and Technology, American University of the Middle East, Kuwait

\begin{abstract}
Received: $\quad 28.07 .2020$
Accepted: $\quad 09.01 .2021$

Published: $\quad 20.03 .2021$
\end{abstract} \\ Article History \\ Research Article

\begin{abstract}
There have been changes since the companies have realized the important role of quality improvement in their success. If they are able to produce high quality products and satisfy demands, then they can survive in competitive global markets. Quality improvement applications aim to decrease variability, which leads to less cost, production time, number of defects, scrap, rework and more customer satisfaction. Quality can be improved by reducing product variability. On the other hand, uncertainty or subjectivity is a part of many engineering and real life problems. However, these problems cannot be solved by traditional methods. This study focuses on constructing Xbar and $S$ control charts in fuzzy environment. The approach is developed by considering the theoretical structure of the Shewhart control charts. The core of the approach depends on the combination of parametric interval estimation and fuzzy statistics. Control limits and samples are presented by fuzzy numbers which ensures to maintain fuzziness in control charts. An important property of the approach is that the fuzzy charts can be reduced to Shewhart control charts. A simulation study was conducted for the performance evaluation of fuzzy Xbar and $S$ control charts. The proposed fuzzy control chart is sensitive to process mean shifts and variance changes, and outperforms the traditional control charts under the changes of variance. In addition, an example from the literature shows that the approach is an effective way of presenting fuzziness in the quality characteristics,
\end{abstract} \\ which enables the approach to have high applicability to the real life problems.
}

Keywords - Confidence intervals, fuzzy numbers, fuzzy set theory, fuzzy statistics, quality control charts,

\section{Introduction}

Quality improvement is a systemic approach aims to improve the performance of systems. It makes controllable and measurable changes that lead to better outcomes and can be applied to any area. Understanding and improving quality are the main factors for a company or organization to achieve its goals such as increasing profit, efficiency, market share, growth ...etc. Quality of production processes can be improved by the reducing the variability of products. Quality and variability are inversely proportional. Having low variability is the main way of reducing waste, production time and costs, and improving the performance and quality of processes.

Monitoring is the first step of quality improvement methods. In 1924 Walter A. Shewhart who is often considered the pioneer of statistical process control, developed quality control charts. Shewhart control charts are the most commonly referred statistical quality control tools used to monitor processes. These charts are graphical displays of quality characteristics that have been measured or observed over time. If sample values fall within the control limits which are two horizontal lines calculated by the sample data, with a random pattern, the process is said to be in control, otherwise the process is out of control and necessary actions should be taken.

\footnotetext{
1 (D) nilufer.alakoc@aum.edu.kw

*Corresponding Author
} 
These traditional control charts are based on random precise data of the quality characteristics. However, uncertainty is the nature of the real life problems, systems, and ignored by the traditional control charts. Sources of uncertainty arise from lack of precise information, such as not fully reliable information due to measurement error, incomplete data, instrument noise or environmental factors. These sources can occur at any point of data collection. For example, a measurement of 0.01 might necessitate a greater precision such as 0.01008. Lack of calibration of measuring instruments or calibration which is not suitable for the production environment might cause inaccurate measurements. Classification of products such as defective non-defective, conforming non-conforming might not be appropriate in some situations. Intermediate states might be required. Judgement of human inspectors might be another reason for uncertainty: a defective product might be non-defective for another person.

Since fuzzy set theory was introduced by Zadeh in 1965 it has been integrated with statistical process control to handle uncertainty in data or human subjectivity. Combination of fuzzy theory and statistical quality control has been studied by many researchers. Various different approaches, methods and applications have been proposed. These studies have been developed from many different points of view but the main objective is same: dealing with uncertainty and fuzziness in process control.

The previous studies were mainly developed on linguistic data. Raz \& Wang (1990), Wang \& Raz (1990), Kanagawa Tamaki \& Ohta (1993) and Gulbay, Kahraman \& Ruan (2004) proposed approaches for monitoring attribute data which are in linguistic forms. Chen \& Yeh (2004) developed a two stages fuzzy approach for variable sampling interval. In another study, Cheng (2005) developed fuzzy control charts for attributes and generated the fuzzy data by combining the experts' opinion and measurements. Gulbay \& Kahraman (2007) introduced direct fuzzy approach (DFA) for c control chart and compared with the previous approaches using defuzzification methods. Hsieh, Tong \& Wang, (2007) proposed a fuzzy control chart which is based on engineering experiences and fuzzy theory. A fuzzy approach for constructing attributes control chart in multistage process was presented by Engin, Elik \& Kaya (2008). The approach is based on acceptance sampling and solved by genetic algorithms. Amirzadeh, Mashinchi \& Parchami (2009) proposed an approach for attributes. Although the approach was proposed for constructing fuzzy p control charts; as data represents the degree of nonconformity of items, the technique of the fuzzy chart is similar to traditional $\bar{x}$ and s control charts. Shu \& Wu (2010) emphasized the critical role of fuzzy data in measurements of quality characteristics and they proposed a fuzzy p chart with permissibly function. Beside these, Wang, Li \& Yasuda (2014) introduced fuzzy c chart monitored with weighted possibilistic mean and weighted interval valued possibilistic mean of fuzzy numbers. Thaga \& Sivasamy (2015) developed transition probability approach based on markov chain theory for linguistic data. Senturk \& Antucheviciene (2017) proposed an interval type-2 fuzzy c-control chart with an application to a food company. Recently, Aslam, Bantan \& Khan (2020) developed a neutrosophic NEWNA np chart.

Applications of fuzzy set theory have been investigated in the field of fuzzy variable control charts by many other authors. The former study on monitoring variable control charts for uncertain observations was developed by Fazel Zarandi, Turksen \& Kashanet, (2006). They proposed plotting control charts by considering uncertain process parameters for both variables and attributes. Another fuzzy chart approach for variables includes a warning line besides its upper control limit (Faraz \& Moghadam, 2007). The shifts between the subgroups of the fuzzy control chart for variables are designed with Pearson goodness of fit statistic. Use of $\alpha$ - cut midrange transformation technique for fuzzy $\bar{X}, \mathrm{R}$ and $S$ control charts are proposed by Senturk \& Erginel (2009).

Faraz \& Shapiro (2010) developed an approach for fuzzy $\bar{X}$ and $S$ charts by considering the assumptions of the Shewhart control charts. The approach is based on a fuzzy region and a graded exclusion measure which defines the degree of a sample out of the in-control region by the percentage area of under fuzzy sets. Shu \& 
Wu (2011) proposed dominance approach for constructing fuzzy $\bar{X}$ and $\mathrm{R}$ control charts. Dominance results of the resolution identity are used to calculate the control limits of the fuzzy chart. Studies have been carried out in the field of fuzzy control charts in which transformation methods are not used. A Fuzzy mean and range control charts are proposed by Mojtaba Zabihinpour, Ariffin, Tang \& Azfanizam, (2014). Observations and control limits are in the form of triangular fuzzy numbers and the processes are defined by percentage of area of the sample mean which remains outside the control limits. They extended their study for a fuzzy $\bar{X}$ and $S$ charts (Mojtaba Zabihinpour, Arif, Tang \& Azfanizam, 2015). Another variable control chart is proposed for non-crisp data by Panthong \& Pongpullponsak, (2016). Shu, Dang, Nguyen, Hsu \& Phan (2017) proposed fuzzy control limits based on results of the resolution identity in fuzzy set theory. Soleymani \& Amiri, (2017) proposed a fuzzy cause selecting control chart to monitor the second stage of a two-stage process where the quality characteristic of the second stage belongs to fuzzy sets in Phase I analysis. Ercan Teksen \& Anagun, (2018) considered interval type-2 fuzzy sets based on different methods for $\bar{X}$-R control charts. Recently, Mendes, Machado \& Rizol, (2019) compared fuzzy control charts and traditional control charts and presented that fuzzy control chart has greater efficiency than the traditional control charts. Al-Refaie, Obaidat, Fouad \& Hanayneh, (2019) proposed fuzzy variables control charts under linguistic data and development process capability analysis.

Many other researchers have contributed to fuzzy process control works from different point of view including skewed data in fuzzy control charts (Atta, Shoraim, Yahaya, Zain \& Ali, 2016; Yimnak \& Intaramo, 2020), nonparametric fuzzy charts (Momeni \& Shokri, 2019; Wang \& Hryniewicz, 2015), flexible control charts (Pekin Alakoc \& Apaydin, 2018), economic design of individual control chart (Wang \& Chen, 1995; Chen, Chang \& Chiu, 2008), fuzzy inference control system (Saricicek \& Cimen, 2011), charts for auto correlated fuzzy observations (Sadeghpour Gildeh \& Shafiee, 2015), performance of FEV theory control charts with $\alpha$ - cut level fuzzy midrange method for three skewed distributions (Intaramo, 2012), nonrandom patterns of fuzzy control charts and fuzzy run rules (Hsu \& Chen, 2001; Tannock, 2003; Gulbay \& Kahraman, 2006; Chih \& Kuo, 2007; Fazel Zarandi, Alaeddini \& Turksen 2008; Demirli \& Vijayakumar, 2010; Pekin Alakoc \& Apaydin, 2013), detecting mean and variance shifts of a process (Chang \& Aw, 1996; Moameni, Saghaei, \& Ghorbani Salnghooch, 2012; Salnghooch, 2015; Kaya, Erdogan \& Yildiz, 2017), fuzzy multivariate control charts (Taleb Limam \& Hirota, 2006; Moheb Alizadeh, Arshadi Khamseh \& Fatemi Ghomi, 2010; Pastuizaca Fernandez, Carrion Garcia, A. \& Ruiz Barzola, 2015), multi objective design of control charts (Morabi, Owlia, Bashiri \& Doroudyan, 2015), fuzzy CUSUM and EWMA control charts (Senturk, Erginel, Kaya, \& Kahraman, 2014; Akhundjanov \& Pascual, 2015).

Although there are many studies in literature, only a few of them focused on using fuzzy statistics. Fuzzy statistical theory is based on both probability theory and fuzzy set theory. The major contribution of this study is to use fuzzy statistical theory to express uncertain data in quality control charts. Therefore, fuzzy control chart values are thoroughly determined in accordance with the uncertain measurements and the probability theory. The main difficulty of designing a fuzzy control chart is to develop appropriate fuzzy control limits and to present uncertain data. The selection of the limits may lead to different judgments on the process state. In order to overcome this issue, in some existing works it is suggested to use transformation methods, but it is known that these methods cause loss of information. On the other hand, using crisp values directly causes a strict classification and may lead to a wrong decision. In this study, we propose an approach for constructing fuzzy $\bar{X}$ and $S$ control charts, based on confidence interval estimation and fuzzy sets. We conduct a computational simulation study and compare the proposed fuzzy control charts with Shewhart control charts for various mean and variance shifts. The average run length statistics present that the fuzzy control chart is more sensitive to variance shifts than the Shewhart control chart. 


\section{Materials and Methods}

\subsection{Statistical Background}

Let $X_{1}, X_{2}, \ldots, X_{\mathrm{n}}$ be a random sample with probability density function $\mathrm{N}\left(\mu, \sigma^{2}\right)$ and mean and standard deviation of the sample are crisp numbers. If all of the $100(1-\alpha) \%$ confidence intervals on $\mu$ for different significance levels are placed, one on top of the other, then a triangular shaped fuzzy number is produced as fuzzy estimator of $\mu$ (Buckley, 2006). For this estimator, the confidence limits are continuous nonlinear functions of the significance level and a $100(1-\alpha) \%$ confidence interval equals to $\alpha$ - cut set of a fuzzy number denoted by $\tilde{\mu}=\left[\mu_{1}(\alpha), \mu_{2}(\alpha)\right]$ where $\tilde{\mu}$ is a crisp set of elements whose membership degrees are greater than or equal to the specified value of $\alpha$. An example triangular fuzzy estimator when $0.001 \leq \alpha \leq 1$ is displayed in Figure 1 where 0.001 is an arbitrary value.

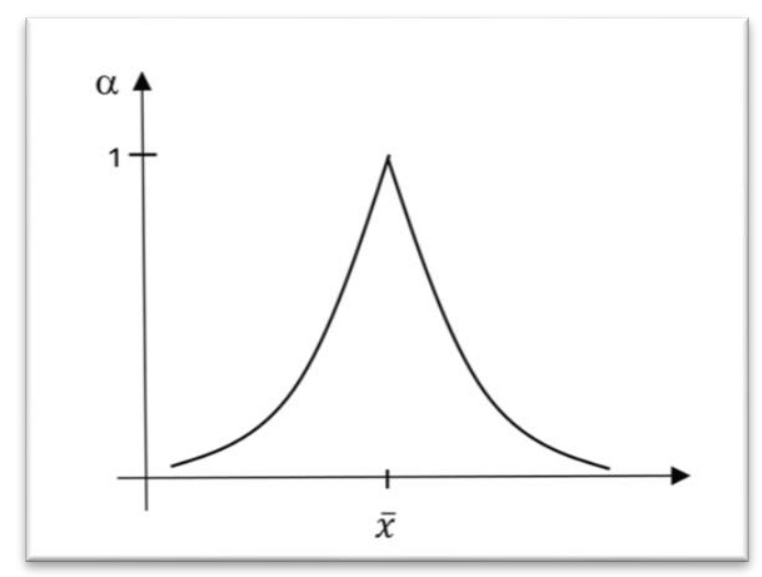

Figure 1. An example: Fuzzy estimator of $\mu$

The concept of confidence interval estimation on a single parameter can be extended to several parameters. Let $X_{1}, X_{2}, \ldots, X_{\mathrm{n}}$ be a random sample from a normal distribution with mean $\mu$ and variance $\sigma^{2}$, then simultaneous confidence region for the mean and the variance is estimated by a parameter space, which includes all possible combinations of the parameters. A joint confidence region for the mean and variance of a normal distribution is formed by the independence property of $\bar{x}$ and $s^{2}$. Since, $\frac{\bar{x}-\mu}{\sigma / \sqrt{n}}$ and $\frac{(n-1) s^{2}}{\sigma^{2}}$ are each pivotal quantities, we may find numbers $q_{1}, q_{2}^{\prime}$ and $q_{2}^{\prime \prime}$ such that 2.1 and 2.2.

$P\left(-q_{1} \leq \frac{\bar{x}-\mu}{\sigma / \sqrt{n}} \leq q_{1}\right)=1-\gamma_{1}$
$P\left(q_{2}^{\prime} \leq \frac{(n-1) s^{2}}{\sigma^{2}} \leq q_{2}^{\prime \prime}\right)=1-\gamma_{2}$

Also since, $\frac{\bar{x}-\mu}{\sigma / \sqrt{n}}$ and $\frac{(n-1) s^{2}}{\sigma^{2}}$ are independent (Mood, Graybill \& Boes 2001) we have joint probability which given in 2.3:

$P\left(-q_{1} \leq \frac{\bar{x}-\mu}{\sigma / \sqrt{n}} \leq q_{1} ; q_{2}^{\prime} \leq \frac{(n-1) s^{2}}{\sigma^{2}} \leq q_{2}^{\prime \prime}\right)=\left(1-\gamma_{1}\right)\left(1-\gamma_{2}\right)$ 
where $100\left(1-\gamma_{1}\right) \%$ and $100\left(1-\gamma_{2}\right) \%$ are confidence levels. The inequalities in 2.3 present a region in the parameter space, which can be drawn by plotting its boundaries where the $x$ axis and $y$ axis are $\mu$ and $\sigma^{2}$, respectively. Figure 2 presents simultaneous confidence region of mean and variance (Mood, Graybill \& Boes 2001).

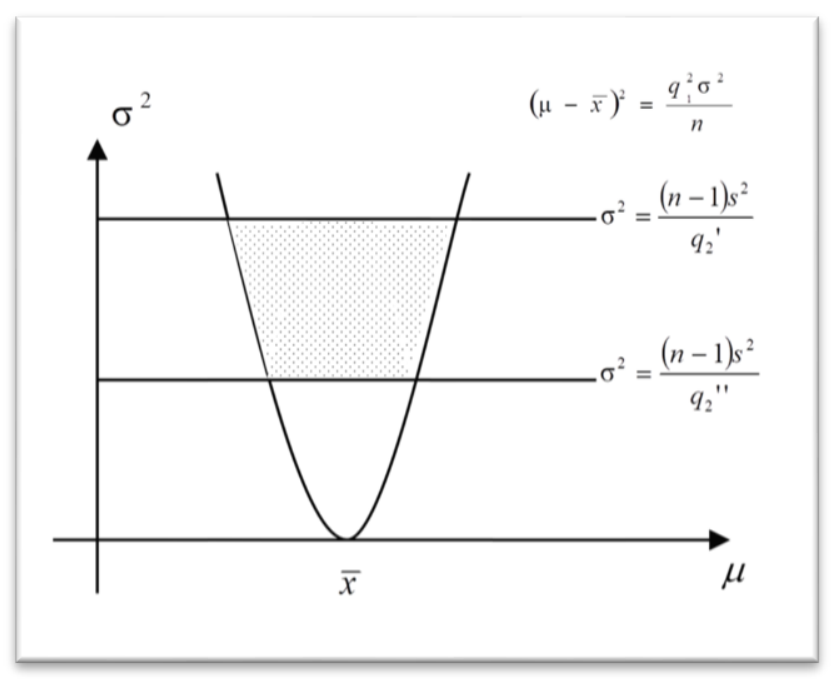

Figure 2. Simultaneous confidence region of $\mu$ and $\sigma^{2}$

\subsection{Design of Fuzzy $\bar{X}$ Control Chart}

Let $m$ samples with size $\mathrm{n}$ are selected (randomly) from a normal distribution with mean $\mu$ and variance $\sigma^{2}$, then; $i^{\text {th }}$ sample mean is estimated by fuzzy estimation method. Based on fuzzy estimation method, $100(1-\alpha) \%$ confidence intervals on the mean of each sample can be calculated for all significance levels. Then, the fuzzy estimate of each sample's mean is a triangular fuzzy number whose $\alpha$ - cut is defined by 2.4 .

$\left[\bar{x}_{i}^{l}[\alpha], \bar{x}_{i}^{u}[\alpha]\right]=\left[\bar{x}_{i}-t_{\alpha / 2, n-1} \frac{s_{i}}{\sqrt{n}}, \bar{x}_{i}+t_{\alpha / 2, n-1} \frac{s_{i}}{\sqrt{n}}\right]$

where $\bar{x}_{i}^{l}[\alpha]$ and $\bar{x}_{i}^{u}[\alpha]$ are the lower and the upper limits of $100(1-\alpha) \%$ interval.

Triangular fuzzy control limits are based on the confidence interval estimations on $\mu+3 \frac{\sigma}{\sqrt{n}}$ and $\mu-3 \frac{\sigma}{\sqrt{n}}$ which are obtained by modifying the simultaneous confidence region of mean and variance approach. In order to have a simultaneous confidence region for $\mu$ and variance $\sigma$, the parabola given in Figure 2 is replaced by the straight lines $\mu=\overline{\bar{x}}+q_{1} \frac{\sigma}{\sqrt{n m}}$ and $\mu=\overline{\bar{x}}-q_{1} \frac{\sigma}{\sqrt{n m}}$ which intersect with the horizontal lines $\sigma=\sqrt{\frac{(n-1) \sum s_{i}^{2}}{q_{2}^{\prime}}}$ and $\sigma=\sqrt{\frac{(n-1) \sum s_{i}^{2}}{q_{2}^{\prime \prime}}}$. Figure 3 shows the simultaneous confidence region which is confined by these lines. 


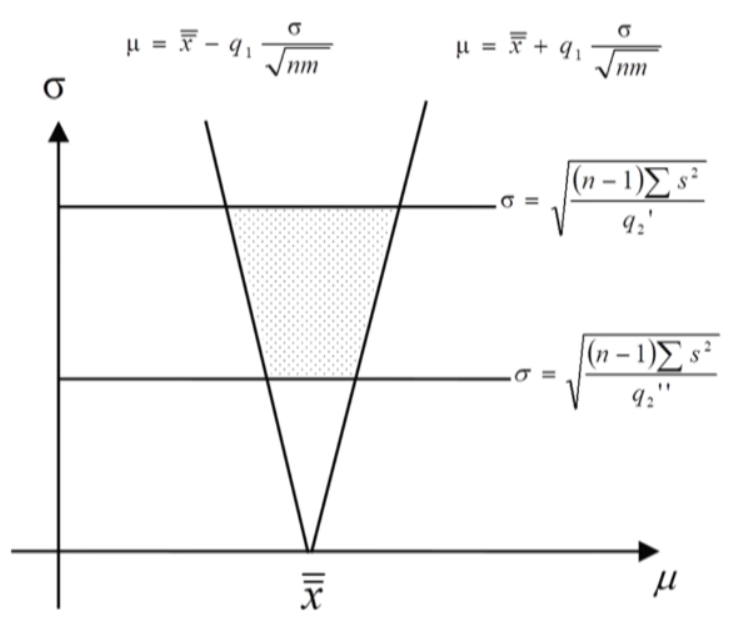

Figure 3. Simultaneous confidence region of $\mu$ and $\sigma$

Derivation of confidence intervals for the limits is an optimization problem in which the simultaneous confidence region is the feasible region. The lower and upper bound values of the confidence interval on the upper fuzzy control limit are obtained by minimizing and maximizing $\mu+3 \frac{\sigma}{\sqrt{n}}$, respectively. Confidence interval estimation on the lower control limit is derived by a similar calculation; minimizing and maximizing $\mu-3 \frac{\sigma}{\sqrt{n}}$. The corner points of the confidence region are the optimum points, which give the required confidence limits. A $100\left(1-\gamma_{1}\right)\left(1-\gamma_{2}\right) \%$ confidence interval estimators of the upper and lower limits are defined in 2.5 and 2.6:

$\overline{\bar{x}}+\sqrt{\frac{(n-1) \sum s_{i}^{2}}{n \chi_{\gamma_{2} / 2, \mathrm{~m}(\mathrm{n}-1)}^{2}}}\left(3-\frac{z_{\gamma_{1} / 2}}{\sqrt{m}}\right)<\mu+3 \frac{\sigma}{\sqrt{n}}<\overline{\bar{x}}+\sqrt{\frac{(n-1) \sum s_{i}^{2}}{n \chi_{1-\gamma_{2} / 2, \mathrm{~m}(\mathrm{n}-1)}^{2}}}\left(\frac{z_{\gamma_{1} / 2}}{\sqrt{m}}+3\right)$

$\overline{\bar{x}}-\sqrt{\frac{(n-1) \sum s_{i}^{2}}{n \chi_{1-\gamma_{2} / 2, \mathrm{~m}(\mathrm{n}-1)}^{2}}}\left(\frac{z_{\gamma_{1} / 2}}{\sqrt{m}}+3\right)<\mu-3 \frac{\sigma}{\sqrt{n}}<\overline{\bar{x}}-\sqrt{\frac{(n-1) \sum s_{i}^{2}}{n \chi_{\gamma_{2} / 2, \mathrm{~m}(\mathrm{n}-1)}^{2}}}\left(3-\frac{z_{\gamma_{1} / 2}}{\sqrt{m}}\right)$

where $\overline{\bar{x}}$ is the mean of $\mathrm{m}$ sample means, $z_{\gamma_{1} / 2}$ is the upper $100\left(\gamma_{1} / 2\right) \%$ point of the standard normal distribution and $\chi_{1-\gamma_{2} / 2, \mathrm{~m}(\mathrm{n}-1)}^{2}$ and $\chi_{\gamma_{2} / 2, \mathrm{~m}(\mathrm{n}-1)}^{2}$ are the lower and upper $100\left(\gamma_{2} / 2\right) \%$ points of the chi-square distribution with $m(n-1)$ degrees of freedom, respectively.

Similarly, we estimate the process mean by the same approach. 2.7 gives a $100(1-\alpha) \%$ confidence interval on the mean, which is used to define fuzzy centre number of the fuzzy $\bar{X}$ control chart.

$\overline{\bar{x}}-z_{\alpha / 2} \sqrt{\frac{\sum s_{i}^{2}}{n m^{2}}}<\mu<\overline{\bar{x}}+z_{\alpha / 2} \sqrt{\frac{\sum s_{i}^{2}}{n m^{2}}}$

Consequently, we use the confidence intervals given in 2.5, 2.6 and 2.7 to plot fuzzy $\bar{X}$ control chart. We define the three sigma $\alpha$ - cut of control limits and center number by 2.8, 2.9 and 2.10: 
$\left[\widetilde{\mathrm{UCL}}_{\bar{\chi}}^{l}[\alpha], \widetilde{\mathrm{UC}} L_{\bar{x}}^{u}[\alpha]\right]=\left[\overline{\bar{x}}+\sqrt{\frac{(n-1) \sum s_{i}^{2}}{n \chi_{\gamma_{2} / 2, \mathrm{~m}(\mathrm{n}-1)}^{2}}}\left(3-\frac{z_{\gamma_{1} / 2}}{\sqrt{m}}\right), \overline{\bar{x}}+\sqrt{\frac{(n-1) \sum s_{i}^{2}}{n \chi_{1-\gamma_{2} / 2, \mathrm{~m}(\mathrm{n}-1)}^{2}}}\left(\frac{z_{\gamma_{1} / 2}}{\sqrt{m}}+3\right)\right]$

$\left[\widetilde{\mathrm{CL}}_{\bar{x}}^{l}[\alpha], \widetilde{\mathrm{CL}}_{\bar{x}}^{u}[\alpha]\right]=\left[\overline{\bar{x}}-z_{\alpha / 2} \sqrt{\frac{\sum s_{i}^{2}}{n m^{2}}}, \overline{\bar{x}}+z_{\alpha / 2} \sqrt{\frac{\sum s_{i}^{2}}{n m^{2}}}\right]$

$\left[\widetilde{L C L}_{\bar{x}}^{l}[\alpha], \widetilde{L C L}_{\bar{x}}^{u}[\alpha]\right]=\left[\overline{\bar{x}}-\sqrt{\frac{(n-1) \sum s_{i}^{2}}{n \chi_{1-\gamma_{2} / 2, \mathrm{~m}(\mathrm{n}-1)}^{2}}}\left(\frac{z_{\gamma_{1} / 2}}{\sqrt{m}}+3\right), \overline{\bar{x}}-\sqrt{\frac{(n-1) \sum s_{i}^{2}}{n \chi_{\gamma_{2} / 2, \mathrm{~m}(\mathrm{n}-1)}^{2}}}\left(3-\frac{z_{\gamma_{1} / 2}}{\sqrt{m}}\right)\right]$

where $\alpha=1-\left(1-\gamma_{1}\right)\left(1-\gamma_{2}\right)$.

$\alpha$ - cut triangular fuzzy numbers are used to graph the fuzzy chart. If $\widetilde{U C L}_{\bar{x}}^{u}[\alpha] \leq \bar{x}_{i}^{l}[\alpha]$ or $\bar{x}_{i}^{u}[\alpha] \leq \widetilde{\operatorname{LCL}}_{\bar{x}}^{l}[\alpha]$, then $\alpha$ - cut of the $i^{\text {th }}$ fuzzy number is beyond the control limits and the process is out of control. Similarly, if $\bar{x}_{i}^{u}[\alpha] \leq \widetilde{U C L}_{\bar{x}}^{l}[\alpha]$ and $\widetilde{\mathrm{CL}}_{\bar{x}}^{u}[\alpha] \leq \bar{x}_{i}^{l}[\alpha]$, then the $\alpha$ - cut of the $i^{\text {th }}$ fuzzy number is completely between the fuzzy limits. Otherwise, the fuzzy number intersects with fuzzy limits, that is $\widetilde{\mathrm{UCL}_{\bar{x}}^{l}}[\alpha]<\bar{x}_{i}^{u}[\alpha] \leq \widetilde{\mathrm{UCL}_{\bar{x}}^{u}}[\alpha]$ or $\widetilde{U C L}_{\bar{x}}^{l}[\alpha]<\bar{x}_{i}^{l}[\alpha] \leq \widetilde{U C L}_{\bar{x}}^{u}[\alpha]$ or $\widetilde{L C L}_{\bar{x}}^{l}[\alpha] \leq x_{i}^{u}[\alpha]<\widetilde{\mathrm{LCL}}_{\bar{x}}^{u}[\alpha]$ or $\widetilde{\mathrm{LCL}}_{\bar{x}}^{l}[\alpha] \leq x_{i}^{l}[\alpha]<\widetilde{\mathrm{LCL}}_{\bar{x}}^{u}[\alpha]$, and the state of the process is not as certain. In this study, the proposed approach defines the process by a decision function, which is developed by considering all possible situations of fuzzy control limits and fuzzy numbers. The process is defined as in control as long as the fuzzy numbers fall within the fuzzy limits under some specified conditions. 2.11 gives the decision criterion.

Process $=\left\{\begin{array}{lr}\text { in control, } & \text { if } f_{i_{\bar{x}, 1}}[\alpha] f_{i_{\bar{x}, 2}}[\alpha] \geq 0 \\ \text { out of control, } & \text { otherwise }\end{array}\right.$

where $f_{i_{\bar{x}, 1}}[\alpha]=\widetilde{\mathrm{UCL}}_{\bar{x}}^{u}[\alpha]-\bar{x}_{i}^{u}[\alpha]$ and $f_{i_{\bar{x}, 2}}[\alpha]=\bar{x}_{i}^{l}[\alpha]-\widetilde{\operatorname{LCL}}_{\bar{x}}^{l}[\alpha]$. If any $\alpha$ - cut of a fuzzy number is completely or partially beyond the fuzzy control limits, then $f_{i_{\bar{x}, 1}}[\alpha]$ or $f_{i_{\bar{x}, 2}}[\alpha]$ is negative and the process is out of control, otherwise the process is in control. In addition to the decision function, we propose a membership function to increase the functionality of the control chart. The function shows degree of being out of control of a fuzzy number. In other words, the degree of deviation from in control state is given by this function. The membership function of the $i^{\text {th }}$ fuzzy number is given in 2.12 .

$\varphi_{i_{\bar{x}}}[\alpha]=\frac{\sum_{k=1}^{4}\left|f_{i_{\bar{x}, k}}[\alpha]\right|+2\left(\bar{x}_{i}^{u}[\alpha]-\bar{x}_{i}^{l}[\alpha]\right)-\left(\widetilde{\mathrm{UCL}} \mathrm{L}_{\bar{x}}^{u}[\alpha]+\widetilde{\mathrm{UCL}} \mathrm{L}_{\bar{x}}^{l}[\alpha]-\widetilde{\mathrm{LCL}}_{\bar{x}}^{u}[\alpha]-\mathrm{LCL}_{\bar{x}}^{l}[\alpha]\right)}{2 \min \left\{\sum_{k=0}^{1}\left|f_{i_{\bar{x}, 2 k+1}}[\alpha]\right|, \sum_{k=1}^{2}\left|f_{i_{\bar{x}, 2 k}}[\alpha]\right|\right\}}$

where $f_{i_{\bar{x}, 3}}[\alpha]=\widetilde{\mathrm{UCL}}_{\bar{x}}^{l}[\alpha]-\bar{x}_{i}^{u}[\alpha]$ and $f_{i_{\bar{x}, 4}}[\alpha]=\bar{x}_{i}^{l}[\alpha]-\widetilde{\operatorname{LCL}}_{\bar{x}}^{u}[\alpha]$. If $\varphi_{i_{\bar{x}}}[\alpha]<1$ for all $i$, then the process is in control. If $\varphi_{i_{\bar{x}}}[\alpha]=0$ then, this denotes that fuzzy number is in desired location: the number lies completely between the fuzzy limits. When $\varphi_{i_{\bar{x}}}[\alpha] \geq 1$, then this is considered as an indication of out of control. The membership degree is not ranged in interval $[0,1]$, which means $\sup \left(\varphi_{i_{\bar{x}}}[\alpha]\right)>1$. This is because of the possible locations of fuzzy numbers on the chart. Although, the membership degree is not limited, a value which is greater than 1 is rarely observed. This situation is observed when the sample is 
completely out of the limits with a high variability. In addition, warning state criteria which increases sensitivity of the fuzzy control chart, is defined as follows: $0<\varphi_{i_{\bar{x}}}[\alpha]<1$.

The value of $\alpha$ affects all the statistics and tightness of the control charts. In other words, $\alpha$ operates like sensitizing rules; selecting a small $\alpha$ means having a more sensitive control chart. If we increase $\alpha$, both of the significance levels $\left(\gamma_{1}\right.$ and $\left.\gamma_{2}\right)$ increase, and this yields to a narrower center number and a smaller joint confidence region. In other words, as $\alpha$ approaches to 1 , the joint confidence region and center number approach to a point. Consequently, when $\alpha$ is 1 , the fuzzy numbers, fuzzy control limits and the fuzzy center number become crisp numbers and the fuzzy control chart approach is simplified to Shewhart control chart.

\subsection{Design of Fuzzy $S$ Control Chart}

Similar to the previous part, fuzzy $S$ control chart is based on fuzzy estimation method: The triangular fuzzy control limits and center number are obtained by adding $100(1-\alpha) \%$ confidence intervals for the standard deviation on top of the others. Let $X_{1}, X_{2}, \ldots, X_{\mathrm{n}}$ be a random sample from a normal distribution with mean $\mu$ and variance $\sigma^{2}$, then the random variable $\frac{(n-1) s_{i}^{2}}{\sigma^{2}}$ has a chi-square distribution with $n-1$ degrees of freedom. Accordingly, $\alpha$ - cut of fuzzy estimate of $i^{\text {th }}$ sample standard deviation is formulated by a 100(1$\alpha) \%$ confidence interval for $\sigma$ which is given in 2.13 .

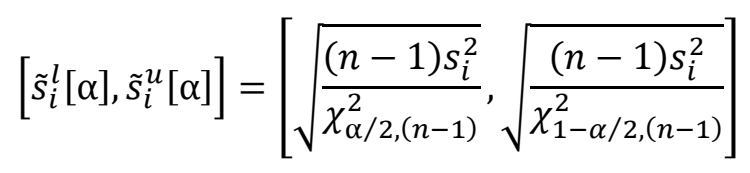

If data consists of $m$ samples each have $n$ measurements, then the random variable $\frac{(n-1) \sum s_{i}^{2}}{\sigma^{2}}$ is distributed with chi-square distribution with $m(n-1)$ degrees of freedom which leads to a $100(1-\alpha) \%$ confidence interval given in 2.14 .

$$
\sqrt{\frac{(n-1) \sum s_{i}^{2}}{\chi_{\alpha / 2, m(n-1)}^{2}}} \leq \sigma \leq \sqrt{\frac{(n-1) \sum s_{i}^{2}}{\chi_{1-\alpha / 2, m(n-1)}^{2}}}
$$

Fuzzy upper and lower control limits are the fuzzy estimates of B $6 \sigma$ and B5 $\sigma$, where B5 and B6 are the Shewhart control chart constants. So, we define $3 \sigma \alpha$ - cut fuzzy center number and control limits by 2.15 , 2.16 and 2.17 .

$$
\begin{aligned}
& {\left[\widetilde{\mathrm{UCL}}{ }_{s}^{l}[\alpha], \widetilde{\mathrm{UCL}} L_{s}^{u}[\alpha]\right]=\left[B_{6} \sqrt{\frac{(n-1) \sum s_{i}^{2}}{\chi_{\alpha / 2, m(n-1)}^{2}}}, B_{6} \sqrt{\frac{(n-1) \sum s_{i}^{2}}{\chi_{1-\alpha / 2, m(n-1)}^{2}}}\right]} \\
& {\left[\widetilde{\mathrm{CL}}_{s}^{l}[\alpha], \widetilde{\mathrm{CL}}_{s}^{u}[\alpha]\right]=\left[\sqrt{\left.\frac{(n-1) \sum s_{i}^{2}}{\chi_{\alpha / 2, m(n-1)}^{2}}, \sqrt{\frac{(n-1) \sum s_{i}^{2}}{\chi_{1-\alpha / 2, m(n-1)}^{2}}}\right]}\right.} \\
& {\left[\widetilde{\mathrm{LCL}}_{s}^{l}[\alpha], \widetilde{\mathrm{LCL}}_{s}^{u}[\alpha]\right]=\left[B_{5} \sqrt{\frac{(n-1) \sum s_{i}^{2}}{\chi_{\alpha / 2, m(n-1)}^{2}}}, B_{5} \sqrt{\frac{(n-1) \sum s_{i}^{2}}{\chi_{1-\alpha / 2, m(n-1)}^{2}}}\right]}
\end{aligned}
$$


We develop the decision and membership functions by the same idea. If $f_{i_{s, 1}}[\alpha] f_{i_{s, 2}}[\alpha]<0$, then the process variability is higher than the specified limits and the process is out of control. Similarly, the membership function which is denoted by $\varphi_{i_{s}}[\alpha]$, shows deviation from the in control state, and the process is out of control, if $\varphi_{i_{s}}[\alpha] \geq 1$. The decision and the membership functions of fuzzy $S$ control chart are given in 2.18 and 2.19.

Process $=\left\{\begin{array}{lr}\text { in control, } & \text { if } f_{i_{s, 1}}[\alpha] f_{i_{s, 2}}[\alpha] \geq 0 \\ \text { out of control, } & \text { otherwise }\end{array}\right.$

$\varphi_{i_{s}}[\alpha]=\frac{\sum_{k=1}^{4}\left|f_{i_{s, k}}[\alpha]\right|+2\left(s_{i}^{u}[\alpha]-s_{i}^{l}[\alpha]\right)-\left(\widetilde{\mathrm{UCL}_{s}^{u}}[\alpha]+\widetilde{\mathrm{UCL}} L_{s}^{l}[\alpha]-\widetilde{\mathrm{LCL}}_{s}^{u}[\alpha]-\widetilde{\mathrm{LCL}}_{s}^{l}[\alpha]\right)}{2 \min \left\{\sum_{k=0}^{1}\left|f_{i_{s, 2 k+1}}[\alpha]\right|, \sum_{k=1}^{2}\left|f_{i_{s, 2 k}}[\alpha]\right|\right\}}$

where $f_{i_{s, 1}}[\alpha]=\widetilde{\mathrm{UCL}}_{s}^{u}[\alpha]-s_{i}^{u}[\alpha], f_{i_{s, 2}}[\alpha]=s_{i}^{l}[\alpha]-\widetilde{\mathrm{LCL}}_{s}^{l}[\alpha], f_{i_{s, 3}}[\alpha]=\widetilde{\mathrm{UCL}}_{s}^{l}[\alpha]-s_{i}^{u}[\alpha]$ and $f_{i_{s, 4}}[\alpha]=$ $s_{i}^{l}[\alpha]-\widetilde{\operatorname{LCL}}_{s}^{u}[\alpha]$.

\subsection{A Numerical Example}

In this section, we demonstrate the fuzzy control chart approach on a well-known example from Montgomery, 2019. The data present the inside diameter measurements of forged automobile engine piston rings of 25 samples. Each consists of five piston rings and data follow normal distribution.

First, triangular fuzzy number estimates of mean and standard deviation are calculated for each sample. $\alpha$ cut of the fuzzy numbers are given in Table 1. Second, triangular fuzzy control limits and center numbers are $\begin{array}{lllllll}\text { computed by } 2.8, & 2.9 & \text { and } 2.10, & \text { and } & 2.15 & 2.16 & \text { and }\end{array}$ $\left[\widetilde{\mathrm{UCL}}_{\bar{x}}^{l}[0.6], \widetilde{\mathrm{UCL}}_{\bar{x}}^{u}[0.6]\right]=[74.0126,74.0171],\left[\widetilde{\mathrm{CL}}_{\bar{x}}^{l}[\alpha], \widetilde{\mathrm{CL}}_{\bar{x}}^{u}[\alpha]\right]=[74.0007,74.0016],\left[\widetilde{\mathrm{LCL}}_{\bar{x}}^{l}[0.6], \widetilde{\mathrm{LCL}}_{\bar{x}}^{u}[0.6]\right]=$ [73.9852,73.9898], $\left[\widetilde{\mathrm{UCL}}_{s}^{l}[0.6], \widetilde{\mathrm{UCL}}_{s}^{u}[0.6]\right]=[0.0190,0.0205],\left[\widetilde{\mathrm{CL}}_{s}^{l}[\alpha], \widetilde{\mathrm{CL}}_{s}^{u}[\alpha]\right]=[0.0099,0.0102]$,

$\left[\widetilde{\mathrm{LCL}}_{s}^{l}[0.6], \widetilde{\mathrm{LCL}}_{s}^{u}[0.6]\right]=[0.0000,0.0000]$. Then, decision function and membership degrees of the fuzzy numbers are calculated for both of the control charts (see Table 1). Finally, the fuzzy control charts are plotted: Figures 4 and 5 show fuzzy $\bar{X}$ control chart and $S$ chart, respectively. 
Table 1

Fuzzy $\bar{X}$ and $S$ control chart example summary statistics.

\begin{tabular}{|c|c|c|c|c|c|c|c|c|c|c|}
\hline Sample & Mean & Stdev & $\bar{x}_{i}^{l}[0.6]$ & $\bar{x}_{i}^{u}[0.6]$ & $f_{i_{\bar{x}, 1}}[0.6] f_{i_{\bar{x}, 2}}[0.6]$ & $\varphi_{i_{\bar{x}}}[0.6]$ & $s_{i}^{l}[0.6]$ & $s_{i}^{u}[0.6]$ & $f_{i_{s, 1}}[0.6] f_{i_{s, 2}}[0.6]$ & $\varphi_{i_{S}}[0.6]$ \\
\hline 1 & 74.0100 & 0.0148 & 74.0064 & 74.0140 & 0.0001 & 0.3032 & 0.0134 & 0.0199 & 0.0000 & 0.6107 \\
\hline 2 & 74.0010 & 0.0075 & 73.9987 & 74.0025 & 0.0002 & 0.0000 & 0.0068 & 0.0101 & 0.0001 & 0.0000 \\
\hline 3 & 74.0080 & 0.0147 & 74.0042 & 74.0118 & 0.0001 & 0.0000 & 0.0134 & 0.0199 & 0.0000 & 0.5889 \\
\hline 4 & 74.0030 & 0.0091 & 74.0007 & 74.0053 & 0.0002 & 0.0000 & 0.0082 & 0.0123 & 0.0001 & 0.0000 \\
\hline 5 & 74.0030 & 0.0122 & 74.0003 & 74.0065 & 0.0002 & 0.0000 & 0.0111 & 0.0165 & 0.0000 & 0.0000 \\
\hline 6 & 73.9960 & 0.0087 & 73.9934 & 73.9978 & 0.0002 & 0.0000 & 0.0079 & 0.0118 & 0.0001 & 0.0000 \\
\hline 7 & 74.0000 & 0.0055 & 73.9986 & 74.0014 & 0.0002 & 0.0000 & 0.0050 & 0.0075 & 0.0001 & 0.0000 \\
\hline 8 & 73.9970 & 0.0123 & 73.9937 & 73.9999 & 0.0001 & 0.0000 & 0.0111 & 0.0165 & 0.0000 & 0.0000 \\
\hline 9 & 74.0040 & 0.0055 & 74.0028 & 74.0056 & 0.0002 & 0.0000 & 0.0050 & 0.0075 & 0.0001 & 0.0000 \\
\hline 10 & 73.9980 & 0.0063 & 73.9964 & 73.9996 & 0.0002 & 0.0000 & 0.0057 & 0.0085 & 0.0001 & 0.0000 \\
\hline 11 & 73.9940 & 0.0029 & 73.9935 & 73.9949 & 0.0002 & 0.0000 & 0.0026 & 0.0039 & 0.0000 & 0.0000 \\
\hline 12 & 74.0010 & 0.0042 & 74.0003 & 74.0025 & 0.0002 & 0.0000 & 0.0038 & 0.0057 & 0.0001 & 0.0000 \\
\hline 13 & 73.9980 & 0.0105 & 73.9957 & 74.0011 & 0.0002 & 0.0000 & 0.0095 & 0.0141 & 0.0001 & 0.0000 \\
\hline 14 & 73.9900 & 0.0153 & 73.9863 & 73.9941 & 0.0000 & 0.7645 & 0.0139 & 0.0207 & 0.0000 & 1.0000 \\
\hline 15 & 74.0060 & 0.0073 & 74.0041 & 74.0079 & 0.0002 & 0.0000 & 0.0066 & 0.0099 & 0.0001 & 0.0000 \\
\hline 16 & 73.9970 & 0.0078 & 73.9946 & 73.9986 & 0.0002 & 0.0000 & 0.0071 & 0.0105 & 0.0001 & 0.0000 \\
\hline 17 & 74.0010 & 0.0106 & 73.9981 & 74.0035 & 0.0002 & 0.0000 & 0.0096 & 0.0143 & 0.0001 & 0.0000 \\
\hline 18 & 74.0070 & 0.0070 & 74.0056 & 74.0092 & 0.0002 & 0.0000 & 0.0063 & 0.0094 & 0.0001 & 0.0000 \\
\hline 19 & 73.9980 & 0.0085 & 73.9960 & 74.0004 & 0.0002 & 0.0000 & 0.0077 & 0.0114 & 0.0001 & 0.0000 \\
\hline 20 & 74.0090 & 0.0080 & 74.0072 & 74.0112 & 0.0001 & 0.0000 & 0.0072 & 0.0108 & 0.0001 & 0.0000 \\
\hline 21 & 74.0000 & 0.0122 & 73.9967 & 74.0029 & 0.0002 & 0.0000 & 0.0110 & 0.0164 & 0.0000 & 0.0000 \\
\hline 22 & 74.0020 & 0.0074 & 73.9997 & 74.0035 & 0.0002 & 0.0000 & 0.0067 & 0.0100 & 0.0001 & 0.0000 \\
\hline 23 & 74.0020 & 0.0119 & 73.9994 & 74.0054 & 0.0002 & 0.0000 & 0.0108 & 0.0161 & 0.0000 & 0.0000 \\
\hline 24 & 74.0050 & 0.0087 & 74.0030 & 74.0074 & 0.0002 & 0.0000 & 0.0079 & 0.0117 & 0.0001 & 0.0000 \\
\hline 25 & 73.9980 & 0.0162 & 73.9941 & 74.0023 & 0.0001 & 0.0000 & 0.0146 & 0.0218 & 0.0000 & 1.0000 \\
\hline
\end{tabular}

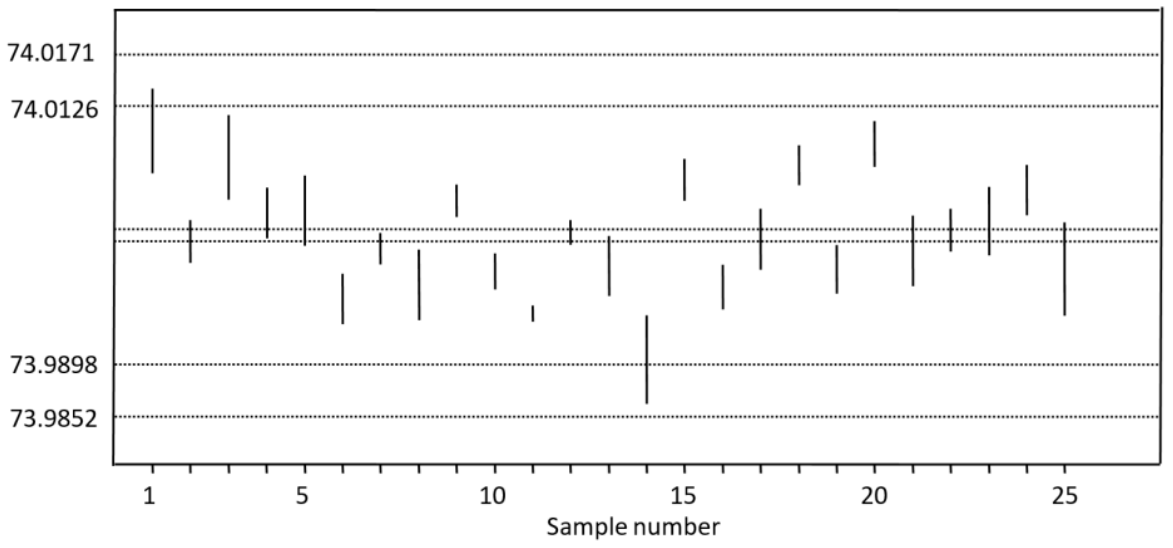

Figure 4. Fuzzy $\bar{X}$ control chart 


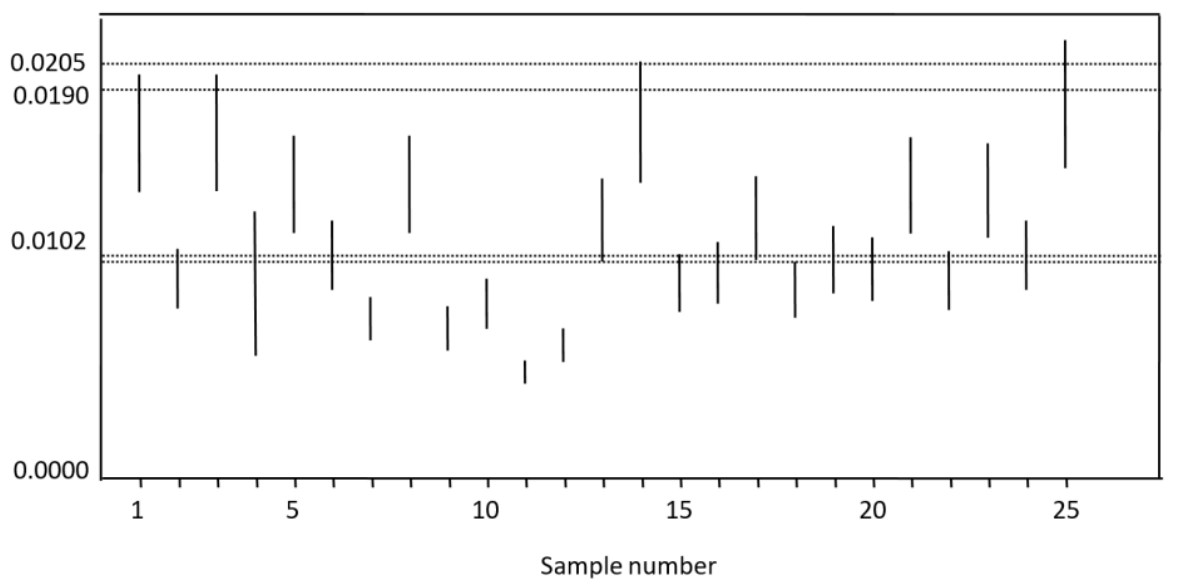

Figure 5. Fuzzy $S$ control chart

Figure 4 shows that except the $1^{\text {st }}$ and the $14^{\text {th }}$ samples all the $\alpha$ - cut of fuzzy numbers are completely between the fuzzy limits. Accordingly, we conclude that based on the $\bar{X}$ chart there is no indication that the process is out of control. The membership degrees denote the same decision since, all function values are less than 1 . In addition, $1^{\text {st }}$ sample which has $\varphi_{1_{\bar{x}}}[\alpha]=0.3032$ and the $14^{\text {th }}$ sample with $\varphi_{14_{\bar{x}}}[\alpha]=0.7645$ indicate warning state which means the process may not be operating properly.

The pattern of fuzzy $\bar{X}$ control chart also gives signals about the result of the fuzzy $S$ control chart since, $\alpha$ cut set of a high variation sample is greater than the set of the low variation. Figure 4 shows greater variation for the $1^{\text {st }}, 3^{\text {rd }}, 14^{\text {th }}$ and $25^{\text {th }}$ samples. The details are presented in fuzzy $S$ control chart. Figure 5 shows that upper limit of $14^{\text {th }}$ and $25^{\text {th }} \alpha$ - cut fuzzy numbers are out of the upper fuzzy control limit with the membership degree 1.000. Consequently, the process is out of control by the $14^{\text {th }}$ and $25^{\text {th }}$ samples.

In this example, we use $\alpha=0.6$. If we want to have more sensitive control charts, the value should be decreased. That is the main difference between the proposed fuzzy charts and Shewhart control charts. As we increase $\alpha$, we would have the same results with Shewhart charts.

\section{Results and Discussion}

Throughout the section, all ARL statistics are provided from 100,000 replications of computer simulation and the random variables are generated from standard normal distribution. The simulations are performed for various combinations of in control ARL, $\alpha$ - cut level and sample size. ARL $\mathrm{A}_{0}$ is fixed at 370 and 500, and three values of $\alpha: 0.4,0.6$ and 0.8 , and two values of sample size: 10 and 15 are considered. Process mean shifts with magnitudes of $\delta_{1} \in\{0.25,0.50,0.75,1.00,1.25,1.50,1.75,2.00,3.00\}$ and changes in variability with magnitudes of $\delta_{2} \in\{0.25,0.50,0.75,1.00,1.25,1.50,2.00\}$ are investigated. The samples are generated from $\mathrm{N}\left(\mu+\delta_{1} \sigma, \sigma\right)$ and $\mathrm{N}\left(\mu, \sigma+\delta_{2} \sigma\right)$. Fuzzy $\bar{X}$ control chart and Shewhart $\bar{X}$ control chart simulation results and are given in Tables 2 and 3, and Figures 6, 7, 8 and 9. 
Table 2

ARL of fuzzy $\bar{X}$ chart and Shewhart $\bar{X}$ chart for the shift of mean when $\alpha=0.4,0.6,0.8, \mathrm{ARL}_{0}=370,500$ and $n=10$.

\begin{tabular}{c|ccccccccc}
\hline & $\begin{array}{c}\text { Shewhart } \\
\bar{X} \text { chart }\end{array}$ & \multicolumn{3}{c|}{ Fuzzy $\bar{X}$ chart } & $\begin{array}{c}\text { Shewhart } \\
\bar{X} \text { chart }\end{array}$ & \multicolumn{3}{c}{ Fuzzy $\bar{X}$ chart } \\
\hline $\begin{array}{c}\text { Shifts } \\
\left(\delta_{1}\right)\end{array}$ & & $\alpha=0.4$ & $\alpha=0.6$ & $\alpha=0.8$ & & $\alpha=0.4$ & $\alpha=0.6$ & $\alpha=0.8$ \\
\hline 0 & 370.3983 & 369.2675 & 369.3401 & 370.5864 & 499.6091 & 500.9779 & 499.0698 & 500.0169 \\
0.25 & 73.2735 & 76.5974 & 74.1125 & 73.4780 & 92.6582 & 96.7288 & 94.0668 & 93.0119 \\
0.50 & 12.8251 & 13.6806 & 13.1365 & 12.8663 & 15.2280 & 16.2006 & 15.5751 & 15.2960 \\
0.75 & 3.7749 & 4.0319 & 3.8593 & 3.7992 & 4.2321 & 4.5206 & 4.3360 & 4.25100 \\
1.00 & 1.7716 & 1.8590 & 1.7987 & 1.7761 & 1.8910 & 1.9959 & 1.9259 & 1.8982 \\
1.25 & 1.2053 & 1.2392 & 1.2169 & 1.2079 & 1.2409 & 1.2790 & 1.2547 & 1.2436 \\
1.50 & 1.0424 & 1.0525 & 1.0458 & 1.0433 & 1.0517 & 1.0634 & 1.0559 & 1.0526 \\
1.75 & 1.0057 & 1.0078 & 1.0063 & 1.0059 & 1.0073 & 1.0099 & 1.0083 & 1.0076 \\
2.00 & 1.0004 & 1.0007 & 1.0005 & 1.0005 & 1.0006 & 1.0009 & 1.0007 & 1.0007 \\
3.00 & 1.0000 & 1.0000 & 1.0000 & 1.0000 & 1.0000 & 1.0000 & 1.0000 & 1.0000 \\
\hline
\end{tabular}

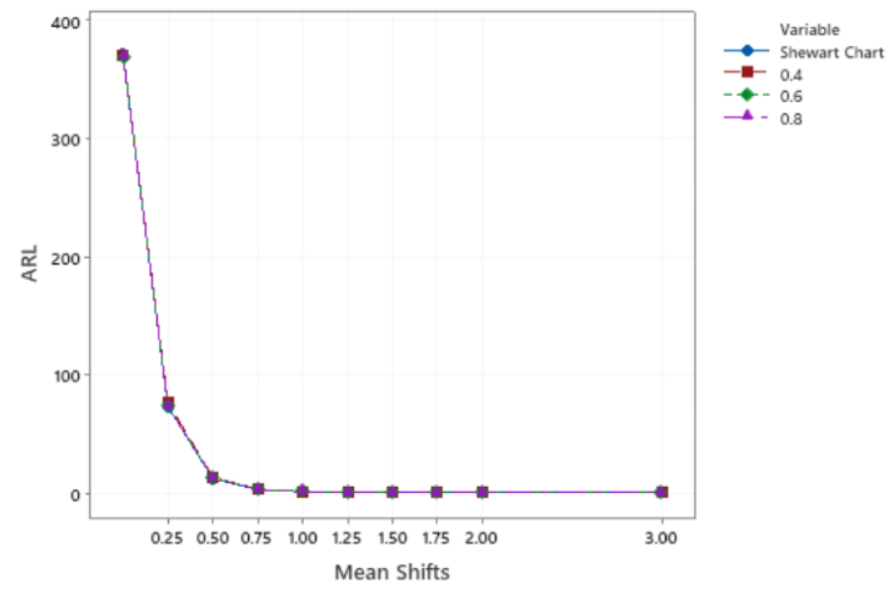

Figure 6. Plot of ARL versus mean shifts for Shewhart $\bar{X}$ chart and fuzzy $\bar{X}$ charts, $\mathrm{ARL}_{0}=370$

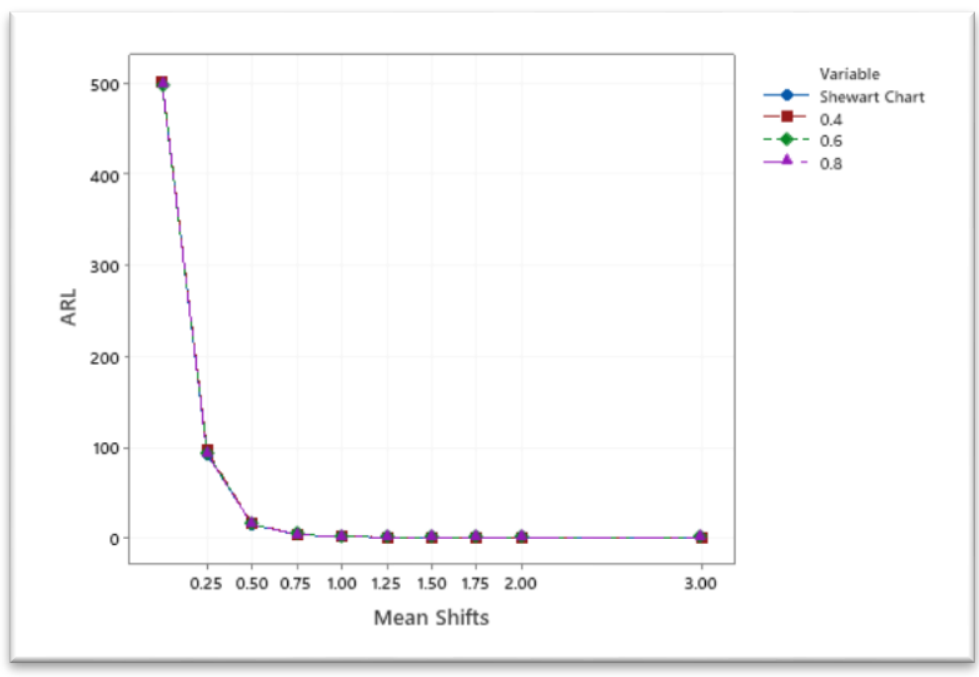

Figure 7. Plot of ARL versus mean shifts for Shewhart $\bar{X}$ chart and fuzzy $\bar{X}$ charts, $\mathrm{ARL}_{0}=500$ 
Table 3

ARL of fuzzy $\bar{X}$ chart and Shewhart $\bar{X}$ chart for the changes in variability when $\alpha=0.4,0.6,0.8, \mathrm{ARL}_{0}=$ 370,500 and $n=10$.

\begin{tabular}{c|cccc|cccc}
\hline & \multicolumn{3}{|c|}{$\mathrm{ARL}_{0}=370$} & \multicolumn{3}{c}{$\mathrm{ARL}_{0}=500$} \\
\\
\hline & $\begin{array}{c}\text { Shewhart } \\
\bar{X} \text { chart }\end{array}$ & \multicolumn{3}{c}{ Fuzzy $\bar{X}$ chart } & $\begin{array}{c}\text { Shewhart } \\
\bar{X} \text { chart }\end{array}$ & \multicolumn{3}{c}{ Fuzzy $\bar{X}$ chart } \\
\hline $\begin{array}{c}\text { Changes } \\
\left(\delta_{2}\right)\end{array}$ & & $\alpha=0.4$ & $\alpha=0.6$ & $\alpha=0.8$ & & $\alpha=0.4$ & $\alpha=0.6$ & $\alpha=0.8$ \\
\hline 0.25 & 60.9939 & 38.8686 & 45.9998 & 53.1343 & 74.4272 & 47.0730 & 55.7550 & 64.6926 \\
0.50 & 21.9779 & 11.7383 & 14.6946 & 18.0115 & 25.3817 & 13.3060 & 16.8254 & 20.7548 \\
0.75 & 11.5639 & 5.7343 & 7.3219 & 9.2302 & 12.9126 & 6.2558 & 8.0971 & 10.2481 \\
1.00 & 7.4842 & 3.5648 & 4.6290 & 5.8863 & 8.1735 & 3.8262 & 5.0134 & 6.4022 \\
1.25 & 5.4818 & 2.5890 & 3.3635 & 4.2862 & 5.8945 & 2.7451 & 3.5822 & 4.6007 \\
1.50 & 4.3452 & 2.0600 & 2.6635 & 3.3918 & 4.6198 & 2.1642 & 2.7980 & 3.5944 \\
2.00 & 3.1515 & 1.5177 & 1.9386 & 2.4658 & 3.3002 & 1.5660 & 2.0165 & 2.5698 \\
\hline
\end{tabular}

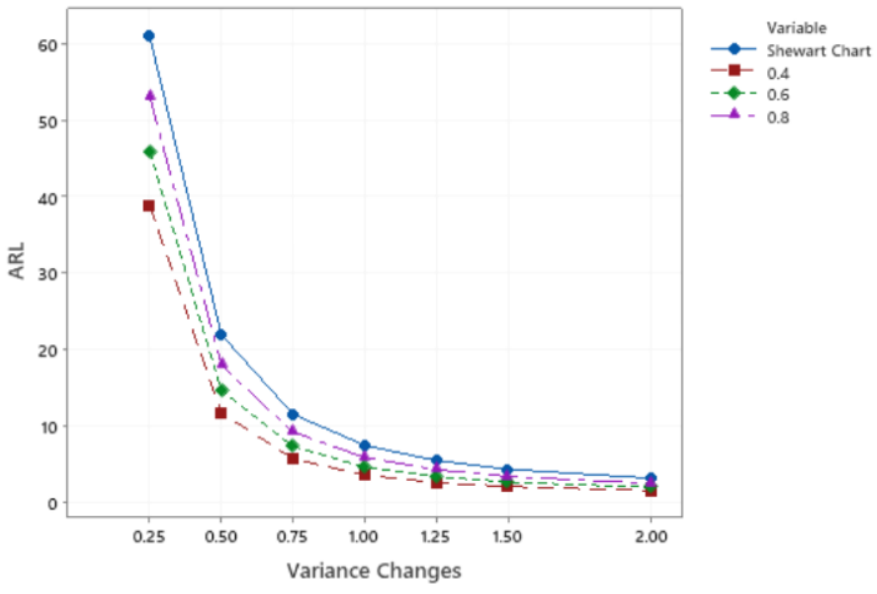

Figure 8. Plot of ARL versus variance changes for Shewhart $\bar{X}$ chart and fuzzy $\bar{X}$ charts, $\mathrm{ARL}_{0}=370$

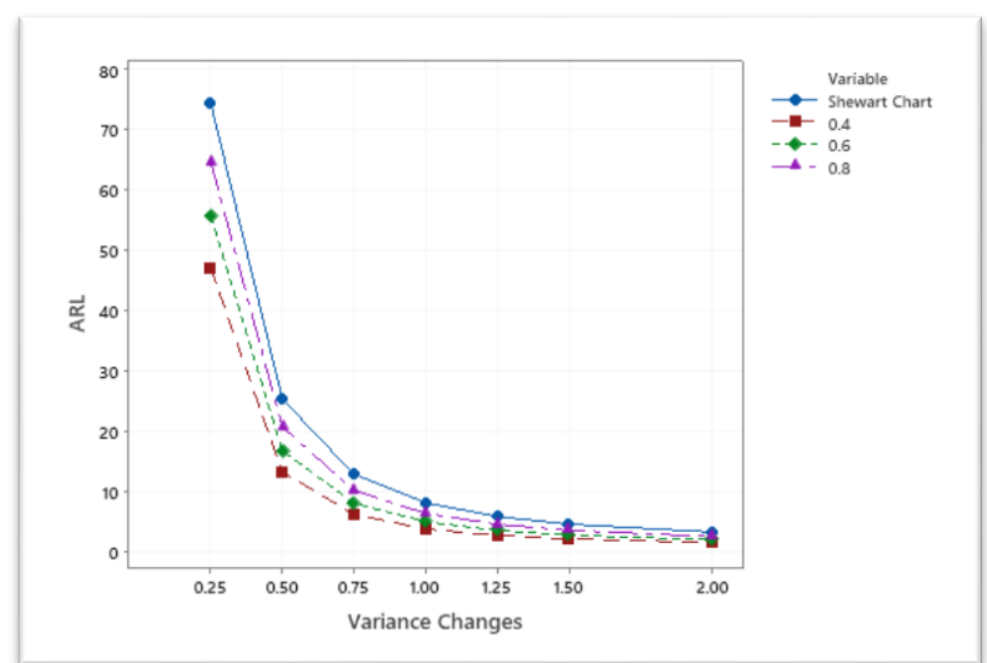

Figure 9. Plot of ARL versus variance changes for Shewhart $\bar{X}$ chart and fuzzy $\bar{X}$ charts, $\mathrm{ARL}_{0}=500$ 
A summary of the conclusions is listed as follows:

When the process mean shifts are considered, the performance of the fuzzy chart is competitive to Shewhart control chart. Table 2 and Figures 6, 7 show that there are no significant differences between the ARL of Shewhart and fuzzy $\bar{X}$ control charts. Moreover, the fuzzy $\bar{X}$ chart performance is not affected by the change of $\alpha$ and $\mathrm{ARL}_{0}$. That is, as $\alpha$ or $\mathrm{ARL}_{0}$ increases the ARL of the fuzzy charts decrease slightly.

Table 2 and Figures 8, 9 show that the fuzzy chart is significantly better than the Shewhart chart for all magnitudes of variation changes. All $\mathrm{ARL}_{1}$ of the fuzzy chart are smaller than the Shewhart chart results. The fuzzy $\bar{X}$ chart performs better for the lower values of $\alpha$. The difference increases as $\alpha$ decreases.

The fuzzy control chart performance approaches to Shewhart control chart performance as $\alpha$ increases. When $\alpha=1$, the fuzzy chart is simplified to Shewhart control chart.

The effect of sample size is also investigated for $n=15$ by reiterating the simulations and similar tables are observed which give the same conclusions.

\section{Conclusion}

In this study, we propose a fuzzy control chart approach. The approach effectively combines traditional control chart concept and fuzzy set theory. Based on fuzzy estimation model of population mean and the theory of joint confidence regions for two parameters, the approach is proposed as an extension of Shewhart $\bar{X}$ and $S$ control charts. The approach uses $\alpha$ - cut of fuzzy numbers and can be reduced to Shewhart control chart. A sensitivity study is conducted in which the proposed fuzzy chart and the Shewhart control chart are compared by the performance measure average run length. The results show that the proposed fuzzy control charts detect even small shifts of process mean and changes of variance effectively. Moreover, the fuzzy chart performs significantly better than Shewhart chart, when a change exists in the variance. As there exist a research gap in integrating the fuzzy statistics in quality control, there can be several extensions of the approach; the most noteworthy is to extend the approach for the other traditional control charts. Moreover, sensitizing rules may be adapted or new rules may be proposed for detecting and interpreting the systemic or nonrandom patterns of the fuzzy charts.

\section{Acknowledgement}

The author received no specific funding for this study.

\section{Author Contributions}

Nilufer Pekin Alakoc confirms sole responsibility for the study: conception and design, analysis and interpretation of results, and manuscript preparation.

\section{Conflicts of Interest}

The author declares no conflict of interest.

\section{References}

Akhundjanov, S.B. \& Pascual, F. (2015). Moving range EWMA control charts for monitoring the Weibull shape parameter. Journal of Statistical Computation and Simulation, 85(9), 1864-1882. DOI: https://doi.org/10.1080/00949655.2014.907574

Al-Refaie, A., Obaidat, A., Fouad, R.H., \& Hanayneh, B., (2019). A fuzzy-logic approach for developing variables control charts and process capability indices under linguistic measurements. Journal of Engineering and Applied Sciences, 14(6). Retrieved from: 
http://www.arpnjournals.org/jeas/research_papers/rp_2019/jeas_0319_7662.pdf

Amirzadeh, V., Mashinchi, M. \& Parchami, A. (2009). Construction of p - charts using degree of nonconformity. Information $\quad$ Sciences, $179(1-2), \quad 150-160 . \quad$ DOI: https://doi.org/10.1016/j.ins.2008.09.010

Aslam, M., Bantan, R.A.R. \& Khan, N. (2020). Design of NEWMA np control chart for monitoring neutrosophic nonconforming items. Soft Computing, 24, 16617-16626. DOI: https://doi.org/10.1007/s00500-020-04964-y

Atta, A.A., Shoraim, M.H.A., Yahaya, S.S.S., Zain, Z. \& Ali, H.A. (2016). Scaled weighted variance S control chart for skewed populations. Journal of Theoretical and Applied Information Technology, 91(1), 61-74. Retrieved from: http://www.jatit.org/volumes/Vol91No1/7Vol91No1.pdf

Buckley, J.J. (2006). Fuzzy Probability and Statistics. Springer-Verlag, Berlin, Germany. Retrieved from: https://www.springer.com/gp/book/9783540308416

Chang, S.I. \& Aw, C.A. (1996). A neural fuzzy control chart for detecting and classifying process mean shifts. International Journal of Production Research, 34(8), 2265-2278. DOI: https://doi.org/10.1080/00207549608905024

Chen, Y.K. \& Yeh, C. (2004). An enhancement of DSI $\bar{X}$ control charts using a fuzzy-genetic approach. International Journal of Advanced Manufacturing Technology, 24, 32-40. DOI: https://doi.org/10.1007/s00170-003-1706-y

Chen, Y.K., Chang, H.H. \& Chiu, F.R. (2008). Optimization design of control charts based on minimax decision criterion and fuzzy process shifts. Expert Systems with Applications, 35(1-2), 207-213. DOI: https://doi.org/10.1016/j.eswa.2007.06.003

Cheng, C. B. (2005). Fuzzy process control: construction of control charts with fuzzy numbers. Fuzzy Sets and Systems, 154(2), 287-303. DOI: https://doi.org/10.1016/j.fss.2005.03.002

Chih, H.W. \& Kuo, W. (2007). Identification of control chart patterns using wavelet filtering and robust fuzzy clustering. Journal of Intelligent Manufacturing, 18, 343-350. DOI: https://doi.org/10.1007/s10845-007-0028-6

Demirli, K. \& Vijayakumar, S. (2010). Fuzzy logic based assignable cause diagnosis using control chart patterns. Information Sciences, 180(17), 3258-3272. DOI: https://doi.org/10.1016/j.ins.2010.05.009

Engin, O., Elik, A.C. \& Kaya, I. (2008). A fuzzy approach to define sample size for attributes control chart in multistage processes: an application in engine valve manufacturing process. Applied Soft Computing, 8(4), 1654-1663. DOI: https://doi.org/10.1016/j.asoc.2008.01.005

Ercan Teksen, H. \& Anagun, A.S. (2018). Different methods to fuzzy $\bar{X}$-R control charts used in production: Interval type-2 fuzzy set example. Journal of enterprise Information Management, 31(6), 848-866. DOI: https://doi.org/10.1108/JEIM-01-2018-0011

Faraz, A. \& Moghadam, M.B. (2007). Fuzzy control chart a better alternative for Shewhart average chart. Quality and Quantity, 41, 375-385. DOI: https://doi.org/10.1007/s11135-006-9007-9

Faraz, A. \& Shapiro, A.F. (2010). An application of fuzzy random variables to control charts. Fuzzy Sets and Systems, 161(20), 2684-2694. DOI: https://doi.org/10.1016/j.fss.2010.05.004

Fazel Zarandi, M. H., Alaeddini, A. \& Turksen, I.B. (2008). A hybrid fuzzy adaptive sampling - Run rules for Shewhart control charts. Information Sciences, 178(4), 1152-1170. DOI: https://doi.org/10.1016/j.ins.2007.09.028 
Fazel Zarandi, M.H., Turksen, I.B. \& Kashan, H. (2006). Fuzzy control charts for variable and attribute quality characteristic. Iranian Journal of Fuzzy Systems, 3(1), 31-44. DOI: https://dx.doi.org/10.22111/ijfs.2006.429

Gulbay, M. \& Kahraman, C. (2006). Development of fuzzy process control charts and fuzzy unnatural pattern analyses. Computational Statistics and Data Analysis, 51(1), 434-451. DOI: https://doi.org/10.1016/j.csda.2006.04.031

Gulbay, M. \& Kahraman, C. (2007). An alternative approach to fuzzy control charts: direct fuzzy approach. Information Sciences, 77(6), 1463-1480. DOI: https://doi.org/10.1016/j.ins.2006.08.013

Gulbay, M., Kahraman, C. \& Ruan, D. (2004). $\alpha$ - Cuts fuzzy control charts for linguistic data. International Journal of Intelligent Systems, 19(12), 1173-1196. Retrieved from: https://onlinelibrary.wiley.com/doi/abs/10.1002/int.20044

Hsieh, K.L., Tong, L.I. \& Wang, M.C. (2007). The application of control chart for defects and defect clustering in IC manufacturing based on fuzzy theory. Expert Systems and Applications, 32(3), 765776. DOI: https://doi.org/10.1016/j.eswa.2006.01.050

Hsu, H.M. \& Chen. Y.K. (2001). A fuzzy reasoning based diagnosis system for Xbar control charts. Journal Intellectual Manufacturing, 12. DOI: https://doi.org/10.1023/A:1008903614042

Intaramo, R. \& Pongpullponsak, A. AUD (2012). Development of fuzzy extreme value theory control charts using $\alpha$-cuts for skewed populations. Applied Mathematical Sciences, 6(117), 5811-5834. Retrieved from: http://www.m-hikari.com/ams/ams-2012/ams-117-120-2012/intaramoAMS117-120-2012.pdf

Kanagawa, A., Tamaki, F. \& Ohta, H. (1993). Control charts for process average and variability based on linguistic data. Intelligent Journal of Production Research, 31(4), 913-922. DOI: https://doi.org/10.1080/00207549308956765

Kaya, I., Erdogan, M. \& Yildiz, C. (2017). Analysis and control of variability by using fuzzy individual control charts. Applied Soft Computing, 51, 370-381. DOI: https://doi.org/10.1016/j.asoc.2016.11.048

Mendes, A.D.S., Machado, M.A.G. \& Rizol, P.M.S.R., (2019). Fuzzy control chart for monitoring mean and range of univariate processess. Pesquisa Operacional, 39(2), 339-357. DOI: http://dx.doi.org/10.1590/0101-7438.2019.039.02.0339

Moameni, M., Saghaei, A. \& Ghorbani Salnghooch, M. (2012). The effect of measurement error on $\tilde{X}-\tilde{R}$ Fuzzy Control Charts. Engineering, Technology \& Applied Science Research, 2(1), 173-176. DOI: https://doi.org/10.48084/etasr.127

Moheb Alizadeh, H., Arshadi Khamseh, A.R. \& Fatemi Ghomi, S.M.T. (2010). Fuzzy development of multivariate variable control charts using the fuzzy likelihood ratio test. Scientia Iranica, 17(2), 150163. Retrieved from: http://scientiairanica.sharif.edu/article_3364.html

Mojtaba Zabihinpour, S., Arif, M., Tang, S. H. \& Azfanizam, A. (2015). Construction of fuzzy Xbar-S control charts with an unbiased estimation of standard deviation for a triangular fuzzy random variable. Journal of Intelligent Fuzzy Systems, 28(6), 2735-2747. DOI: http://dx.doi.org/10.3233/IFS151551

Mojtaba Zabihinpour, S., Ariffin, M.K.A., Tang S.H. \& Azfanizam, A.S. (2014). Fuzzy based approach for monitoring the mean and range of the products quality. Journal of Applied Environmental and Biological Sciences, $4(9), \quad 1-7 . \quad$ Retrieved from: https://www.textroad.com/pdf/JAEBS/J.\%20Appl.\%20Environ.\%20Biol.\%20Sci.,\%204(9)17,\%202014.pdf 
Momeni, F. \& Shokri, S. (2019). Nonparametric Shewhart-type quality control charts in fuzzy environment. International Journal of Applied Operational Research, 9(3), 28-44. Retrieved from: http://ijorlu.liau.ac.ir/article-1-581-en.html

Montgomery, D.C. (2019). Introduction to Statistical Quality Control ( $8^{\text {th }}$ ed.). John Wiley \& Sons Inc., NY, USA. Retrieved from: https://www.wiley.com/enus/Introduction+to+Statistical+Quality+Control\%2C+8th+Edition-p-9781119399308

Mood, A.M., Graybill, A.F. \& Boes, D.C. (2001). Introduction to the theory of Statistics (3 ${ }^{\text {rd }}$ ed.) McGrawHill, New York. Retrieved from: https://www.mheducation.co.in/introduction-to-the-theory-ofstatistics-9780070445208-india

Morabi, Z.S., Owlia, M.S., Bashiri, M. \& Doroudyan, M.H. (2015). Multi-objective design of $\bar{X}$ control charts with fuzzy process parameters using the hybrid epsilon constraint PSO. Applied Soft Computing Journal, 30, 390-399. DOI: https://doi.org/10.1016/j.asoc.2015.01.065

Panthong C. \& Pongpullponsak, A. (2016). Non-normality and the fuzzy theory for variable parameters control charts. Thai Journal of Mathematics, 14(1), 203-213. Retrieved from: http://thaijmath.in.cmu.ac.th/index.php/thaijmath/article/viewFile/1590/779

Pastuizaca Fernandez, M.N., Carrion Garcia, A. \& Ruiz Barzola, O. (2015). Multivariate multinomial $T^{2}$ control chart using fuzzy approach. International Journal of Production Research, 53(7), 2225-2238. DOI: https://doi.org/10.1080/00207543.2014.983617

Pekin Alakoc, N. \& Apaydin, A. (2013). Sensitizing rules for fuzzy control charts. World Academy Science Engineering Technology, 77, 679-683. Retrieved from: https://publications.waset.org/429/sensitizingrules-for-fuzzy-control-charts

Pekin Alakoc, N. \& Apaydin, A. (2018). A fuzzy control chart approach for attributes and variables. Engineering Technology and Applied Science Research, 8(5), 3360-3365. DOI: https://doi.org/10.48084/etasr.2192

Raz, T. \& Wang, J.H. (1990). Probabilistic and memberships approaches in the construction of control charts for linguistic data. Production Planning and Control, 1(3), 147-157. DOI: https://doi.org/10.1080/09537289008919311

Sadeghpour Gildeh, B. \& Shafiee, N. (2015). X-MR control chart for autocorrelated fuzzy data using Dp,qdistance. International Journal of Advanced Manufacturing Technology, 18(1), 1047-1054. DOI: https://doi.org/10.1007/s00170-015-7199-7

Saricicek, I. \& Cimen, O. (2011). A new diagnosis system based on fuzzy reasoning to detect mean and/or variance shifts in a Process. International Journal of Innovative Computing, Information and Control, 7(12), 6935-6948. Retrieved from: http://www.ijicic.org/10-08098-1.pdf

Senturk, S. \& Antucheviciene, J. (2017). Interval type-2 fuzzy c-control charts: Na application in a food company. Informatica, 28(2), 269-283. DOI: https://doi.org/10.15388/Informatica.2017.129

Senturk, S. \& Erginel, N. (2009). Development of fuzzy $\tilde{\bar{X}}-\tilde{R}$ and $\tilde{\bar{X}}-\tilde{S}$ control charts using $\alpha$ - cuts. Information Sciences, 179(10), 1542-1551. DOI: https://doi.org/10.1016/j.ins.2008.09.022

Senturk, S., Erginel, N., Kaya, I. \& Kahraman, C. (2014). Fuzzy exponentially weighted moving average control chart for univariate data with a real case application. Applied Soft Computing, 22, 1-10. DOI: https://doi.org/10.1016/j.asoc.2014.04.022

Shu, M.H. \& Wu, H.C. (2010). Monitoring imprecise fraction of nonconforming items using p control charts. Journal of Applied Statistics, 37(8), 1283-1297. DOI: https://doi.org/10.1080/02664760903030205 
Shu, M.H. \& Wu, H.C. (2011). Fuzzy $\bar{X}$ and R control charts: fuzzy dominance approach. Computers \& Industrial Engineering, 61(3), 676-686. DOI: https://doi.org/10.1016/j.cie.2011.05.001

Shu, M.H., Dang, D.C., Nguyen, T.L., Hsu, B.M. \& Phan, N.S., (2017). Fuzzy $\bar{x}$ and $s$ control charts: a dataadaptability and human-acceptance approach. Complexity, 17, DOI: https://doi.org/10.1155/2017/4376809

Soleymani, P. \& Amiri, A. (2017). Fuzzy cause selecting control chart for monitoring multistage processes. International Journal of Industrial and Systems Engineering, 25(3), 404-422. DOI: https://doi.org/10.1504/IJISE.2017.081920

Taleb, H., Limam, M. \& Hirota, K. (2006). Multivariate fuzzy multinomial control charts. Quality Technology \& Quantitative Management, 3(4), 437-453. DOI: https://doi.org/10.1080/16843703.2006.11673125

Tannock, J.D.T. (2003). A fuzzy control charting method for individuals. International Journal of Production Research, 41(5), 1017-1032. DOI: https://doi.org/10.1080/0020754021000049808

Thaga, K. \& Sivasamy, R. (2015). Control chart based on transition probability approach. Journal of Statistical and Econometric Methods, 4(2), 61-82. Retrieved from: http://www.scienpress. com/Upload/JSEM/Vol\%204_2_3.pdf

Wang, D. \& Hryniewicz, O. (2015). A fuzzy nonparametric Shewhart chart based on the bootstrap approach. International Journal of Applied Mathematics and Computer Science, 25(2), 389-401. DOI: https://doi.org/10.1515/amcs-2015-0030

Wang, D., Li, P. \& Yasuda, M. (2014). Construction of fuzzy control charts based on weighted possibilistic mean. Communications in Statistics-Theory and Methods, 43(15), 3186-3207. DOI: https://doi.org/10.1080/03610926.2012.695852

Wang, J.H. \& Chen, C.H. (1995). Economic statistical np-control chart designs based on fuzzy optimization. International Journal of Quality and Reliability Management, 12(1), 88-92. DOI: https://doi.org/10.1108/02656719510076276

Wang, J.H. \& Raz, T. (1990). On the construction of control charts using linguistic variables. Intelligent Journal of Production Research, 28(3), 477-487. DOI: https://doi.org/10.1080/00207549008942731

Yimnak, K. \& Intaramo, R. (2020). An fuzzy scaled weighted variance S control chart for skewed populations. Thai Journal of Mathematics, 18(1), 53-62. Retrieved from: http://thaijmath.in.cmu.ac.th/index.php/thaijmath/article/viewFile/4035/354354600

Zadeh, L.A. (1965). Fuzzy sets. Information and Control, 8, 338-353. DOI: https://doi.org/10.1016/S00199958(65)90241-X 